\title{
ASSISTÊNCIA ODONTOLÓGICA EM UNIDADE DE TERAPIA INTENSIVA AO PACIENTE PORTADOR DE SÍNDROME DE WERDNIG-HOFFMAN: RELATO DE DOIS CASOS
}

\section{DENTAL ASSISTANCE IN AN INTENSIVE CARE UNIT TO THE PATIENT WITH WERDNIG- HOFFMAN SYNDROME: REPORT OF TWO CASES}

\author{
lúska Cyntia Mariz GALVÃO ${ }^{1}$, Sérgio D’Ávila Lins Bezerra CAVALCANTI², José Eraldo Viana \\ FERREIRA ${ }^{3}$, Rosa Maria Mariz de Melo Sales Marmhoud COURY4 \\ ${ }^{1}$ Graduanda em Odontologia pela Universidade Estadual da Paraíba, Campina Grande, Brasil. \\ ²Doutor em Odontologia pela Universidade de Pernambuco. Professor Doutor do Departamento de Odontologia da Universidade Estadual da \\ Paraíba, Campina Grande, Brasil. \\ ${ }^{3}$ Mestre em Odontologia pela Universidade Estadual da Paraíba, Campina Grande, Brasil. \\ ${ }^{4}$ Especialista em Dentística Restauradora pela Universidade Estadual da Paraíba. Especialista em Morfologia pela Universidade Federal de \\ Pernambuco. Professora do Departamento de Odontologia da Universidade Estadual da Paraíba, Campina Grande, Brasil.
}

Informação sobre o manuscrito

Recebido em: 11 Jan 2021

Aceito em: 19 Nov 2021

\author{
Autor para contato: \\ lúska Cyntia Mariz Galvão \\ Endereço: Rua Francisco Lopes, n. 415, Centenário, \\ Campina Grande - PB. Fone: (83) 99651-6640 \\ e-mail: iuskamaariz@hotmail.com
}

\section{RESUMO}

O objetivo do trabalho foi relatar os casos de dois pacientes portadores de atrofia muscular espinhal (AME) tipo I ou síndrome de Werdnig-Hoffman, internados na Unidade de Terapia Intensiva Pediátrica do Hospital Universitário Alcides Carneiro (HUAC) da cidade de Campina Grande-PB. Relato de caso: Pacientes do gênero masculino, ambos com 8 anos de idade, dependentes de ventilação mecânica, apresentaram manifestação precoce de atrofia e fraqueza muscular progressiva, que inviabilizou o desenvolvimento de habilidades motoras, ocasionando grave comprometimento respiratório. No ambiente de terapia intensiva, no contexto de equipe multidisciplinar, destaca-se o efeito do serviço de assistência odontológica na promoção da qualidade de vida desses pacientes, atuando em especial no controle de patógenos. Considerações finais: As afecções bucais são potenciais fontes de agravamento sistêmico, devendo ser prevenidas e solucionadas por um Cirurgião-Dentista qualificado a trabalhar em ambiente hospitalar, e disposto a alavancar o trabalho da equipe multidisciplinar, garantindo que o cuidado seja de forma integral.

PALAVRAS-CHAVE:

Equipe hospitalar de odontologia. Atrofias musculares espinais da infância. Doenças neuromusculares.

\section{INTRODUÇÃO}

A Atrofia muscular espinhal (AME) é um grupo de doenças neuromusculares, de herança autossômica recessiva, que resultam da degeneração dos neurônios motores da medula espinhal e do tronco cerebral, ocasionando, secundariamente, fraqueza e perda de massa muscular. ${ }^{1}$

\section{Considerando uma classificação} peremptória, existem três formas clínicas de AME, sendo essa classificação baseada na idade de aparecimento da sintomatologia e na intensidade do comprometimento motor da criança.

O tipo I ou síndrome de WerdnigHoffman manifesta-se precocemente, 
acometendo os menores de seis meses de idade, e é a forma mais grave, com mortalidade frequente antes dos dois anos. $O$ tipo II, chamada de AME intermediária, costuma manifestar-se antes dos 18 meses de idade. Já o tipo III ou síndrome de Kugelberg-Welander trata-se de uma forma mais branda, afetando pacientes com mais de 18 meses de vida. $^{2}$

Segundo Marcondes et al. ${ }^{3}$ (2003), na síndrome de Werdnig-Hoffman, a sintomatologia inicia com quadro de hipotonia grave generalizada, ausência da movimentação, evoluindo com comprometimento respiratório e motor. Por ser uma doença neurodegenerativa progressiva e de alta mortalidade, dificilmente os pacientes completam um ano de idade sem suporte adequado.

Este trabalho teve como objetivo descrever a abordagem odontológica hospitalar, e seus desafios, aos portadores da síndrome de Werdnig-Hoffman, através do relato dos casos clínicos de dois pacientes do sexo masculino, internados na Unidade de Terapia Intensiva Pediátrica do Hospital Universitário Alcides Carneiro (HUAC) da cidade de Campina Grande-PB, dependentes de ventilação mecânica total, ofertada por cânula de traqueostomia.

\section{RELATO DE CASO}

$\underline{\text { Relato de caso I }}$
Paciente P.H.A.S., sexo masculino, leucoderma, 8 anos de idade, natural do município de Teixeira-PB, portador da Síndrome de Werdnig-Hoffman, internado atualmente na UTI (Unidade de Terapia Intensiva) Pediátrica do Hospital Universitário Alcides Carneiro (HUAC) da cidade de Campina Grande-PB, apresentando dependência ventilatória total, com admissão datada em 14 de janeiro de 2012, procedente do Hospital CLIPSI, também em Campina Grande-PB, detendo encaminhamento prévio do Hospital Infantil Noaldo Leite da cidade de Patos-PB, onde fora internado no quadragésimo dia de vida, com quadro clínico de fraqueza muscular respiratória e diagnóstico de pneumonia associada à Infecção Respiratória Aguda (IRA).

Durante relato feito à equipe do HUAC, a mãe mencionou ter procurado assistência médica após o filho, ainda recém nascido, apresentar sucessivos episódios de desmaios acompanhados de palidez e sudorese. Além disso, a genitora acrescentou que esses sinais clínicos a preocuparam devido ao fato de um sobrinho, já falecido, diagnosticado com Síndrome de WerdnigHoffman, ter apresentado histórico semelhante.

Conforme prontuário médico intensivista recente, o paciente encontra-se restrito ao leito, normocorado, traqueostomizado, hipersecretivo, acianótico, em ventilação mecânica invasiva do tipo PCV 
(ventilação com pressão controlada), sequelado neurológico, hipoativo reativo, com mímica facial preservada, mantendo contato visual e respondendo, a sua maneira, aos comandos verbais que the são direcionados (Figura 1). Além disso, vale ressaltar que o menor faz uso de SPINRAZA $®$ (nusinersena), após ter obtido a concessão do medicamento em junho de 2019.

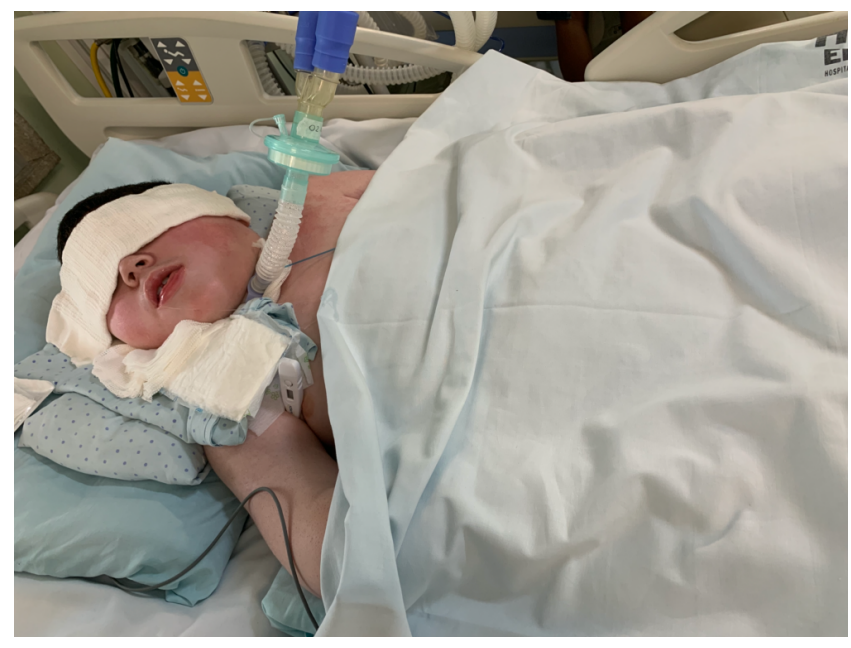

Figura 1. Paciente em seu leito de UTI, traqueostomizado, sendo submetido à rotina diária de monitorização da temperatura corporal, através de termômetro digital.

Durante a trajetória de internação registraramse alguns acontecimentos agravantes do quadro clínico, tais como fratura de fêmur esquerdo durante manipulação em banho, pneumonia nosocomial com diagnóstico microbiológico de Pseudomonas aeruginosa, sepse de foco enteral por vazamento da gastrostomia, e fístula traqueoesofágica com cultura de secreção acusando Klebsiella pneumoniae. A rotina diária na UTI é desempenhada por uma equipe capacitada e intencionada em identificar e suprir as necessidades básicas do paciente, favorecendo uma melhor qualidade de vida. Enquadram-se nessa rotina os cuidados com a VPM (ventilação pulmonar mecânica), horários regulares da dieta por sonda de gastrostomia, administração de analgésicos, antipiréticos e multivitamínicos, limpeza oral com enxaguante bucal, e uso de óleos à base de ácidos graxos essenciais que atuam na cicatrização de feridas e escaras.

No que se referem às condutas terapêuticas, essas são realizadas de forma multiprofissional e interdisciplinar. A atuação do fonoaudiólogo concentra-se na prevenção de distúrbios relacionados à disfagia, utilizando técnicas de alongamento da musculatura orofacial e terapia indireta de deglutição com estimulação tátiltérmica (fria) em região intra e extra-oral. A terapia ocupacional promove estimulação sensorial e, junto ao suporte psicológico, atividades lúdicas com a criança. Quanto aos cuidados da fisioterapia, esses englobam a área motora e respiratória (Figura 2).

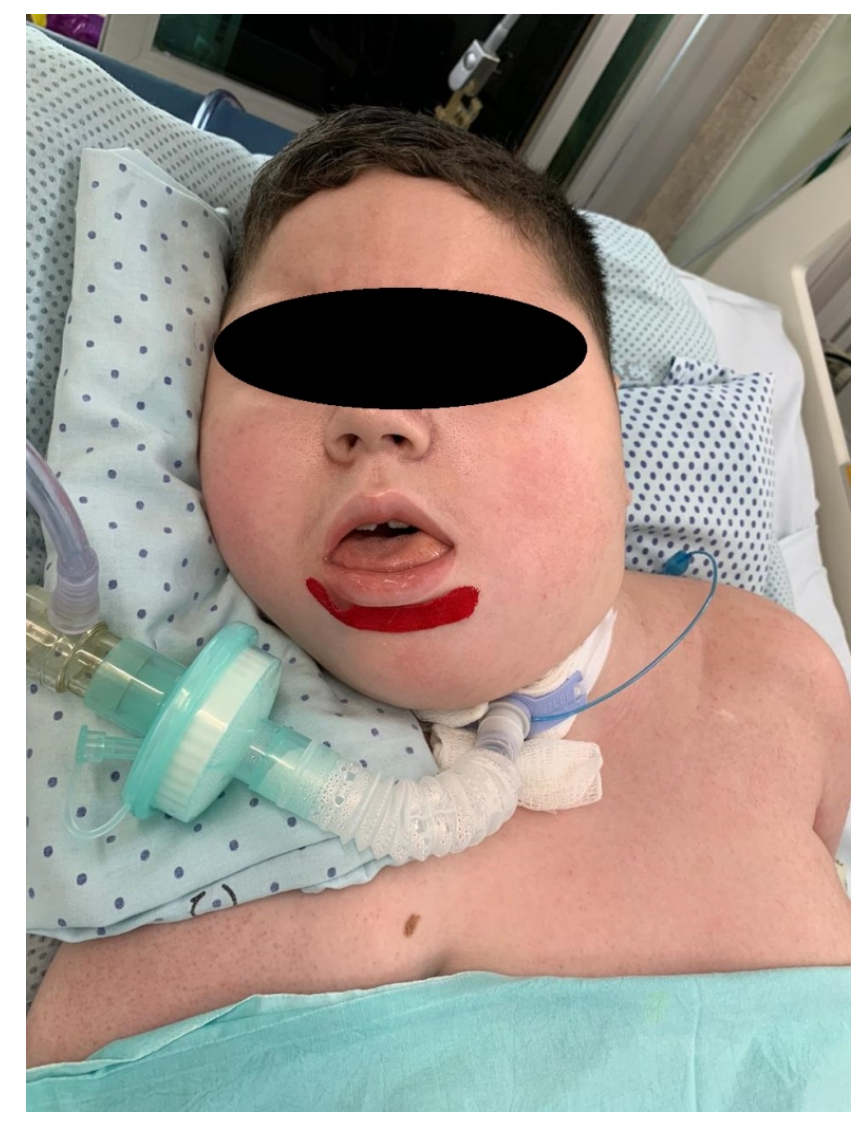

Figura 2. Utilização de bandagem funcional (Kinesio Tapping): Técnica realizada pelos profissionais da fisioterapia e da fonoaudiologia, visando à melhora da motricidade orofacial. 
A odontologia complementa os cuidados prestados ao paciente, através de visitas semanais, que oferecem desde profilaxia a exodontias, elevando a saúde bucal de deficiente para satisfatória, e contribuindo para a redução de infecções respiratórias associadas à ventilação mecânica.

De acordo com os registros em prontuários, a primeira vez em que a equipe de odontologia hospitalar foi acionada ocorreu em 21 de março de 2017, ocasião em que foram solicitados raio- $x$ da face e de crânio, e observou-se erupção ectópica dos dentes 11,21 e 26.

Após essa visita, foram contabilizados mais seis atendimentos no referido ano, sendo possível realizar diagnóstico de doença periodontal; passagem das orientações de higiene oral à mãe, enfatizando o uso de óleo de girassol nos lábios, e ressaltando a importância de trocar a escova dental mensalmente ou imediatamente após episódios de processos infecciosos; aplicação de uma técnica auxiliar na aceleração da esfoliação dos dentes 61 e 51 ; e exodontias dos dentes 52 e 62.

Em 2018, manteve-se o cuidado contínuo com os dentes em rizólise $(53,63$, 73, e 83), devido ao risco de aspiração ser intensificado pela presença de sialorreia; solicitou-se novamente raio-x anterior da face e raio-x posterior do crânio, com a intenção de analisar a cronologia do desenvolvimento craniofacial, não sendo possível realizar tal exame complementar em consequência do quadro clínico que o paciente apresentava.

As exodontias dos dentes 53, 73 e 83 foram executadas em 2019, ocorrendo sem intercorrências, mas sendo necessário uso da antibioticoterapia profilática, e recomendado o regime de dose única de Amoxicilina 1g, uma hora antes do início da intervenção cirúrgica.

Durante os procedimentos, realizava-se antissepsia intrabucal com clorexidina 0,12\% (Figura 3 A e B); adaptação do abridor de boca infantil; anestesia infiltrativa; sindesmotomia; exodontia propriamente dita (técnica I); e hemostasia através da compressão com gaze estéril (Figura 4 A, B, C e D).

Ademais, vale citar que as consultas para monitoramento da higiene oral do paciente foram realizadas durante todo 0 ano, bem como medidas preventivas, a exemplo de profilaxias e aplicação tópica de flúor, além de tratamentos periodontais e restauradores com resina fotoativada (Figura 5).

Por meio de questionário estruturado com 16 perguntas, aplicado à mãe do menor, tornou-se possível coletar dados complementares aos obtidos em 
prontuários, principalmente sobre o que concerne ao pré-natal, parto e puerpério.

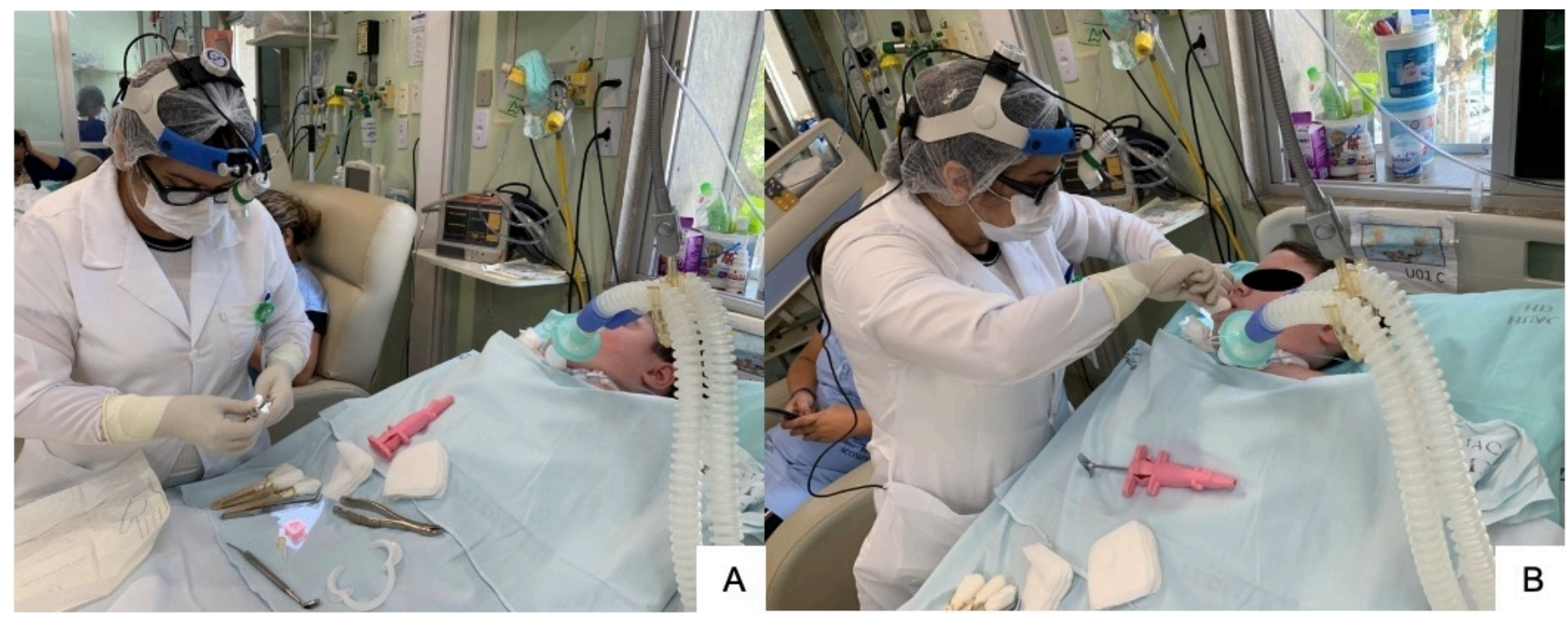

Figura 3. Atuação da odontologia hospitalar em momento pré-operatório. (A) Disposição dos instrumentais cirúrgicos; (B) Antissepsia intrabucal realizada com "boneca de gaze" embebida de solução de clorexidina $0,12 \%$.

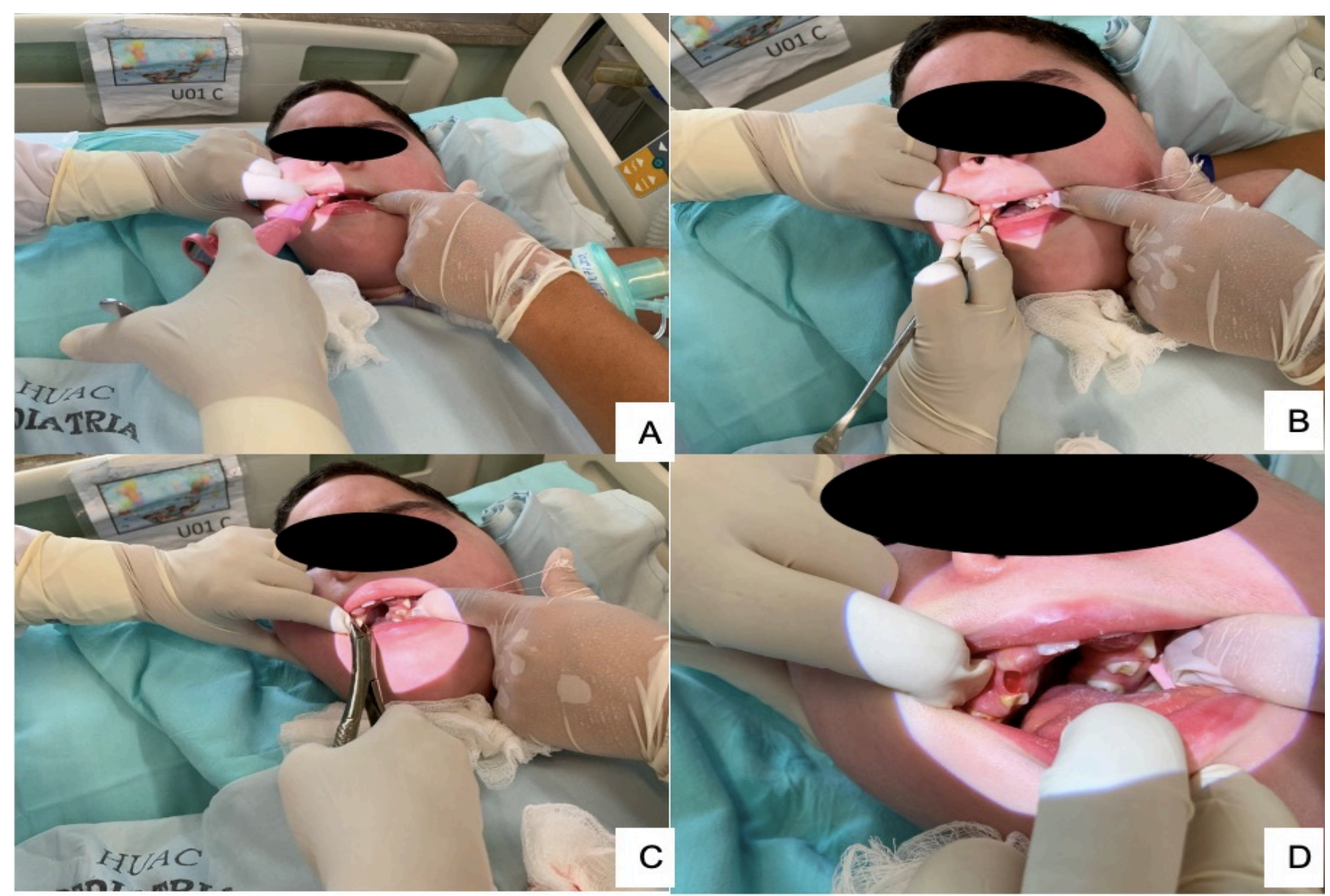

Figura 4. Exodontia do dente 53 por fórceps (técnica I), na qual se realizou: (A) anestesia infiltrativa com lidocaína a $2 \%$ com adrenalina a 1:100000; (B) sindesmotomia; (C) movimentos de lateralidade e tração. Na figura (D), o aspecto do alvéolo dentário após hemostasia por compressão direta com gaze estéril. 


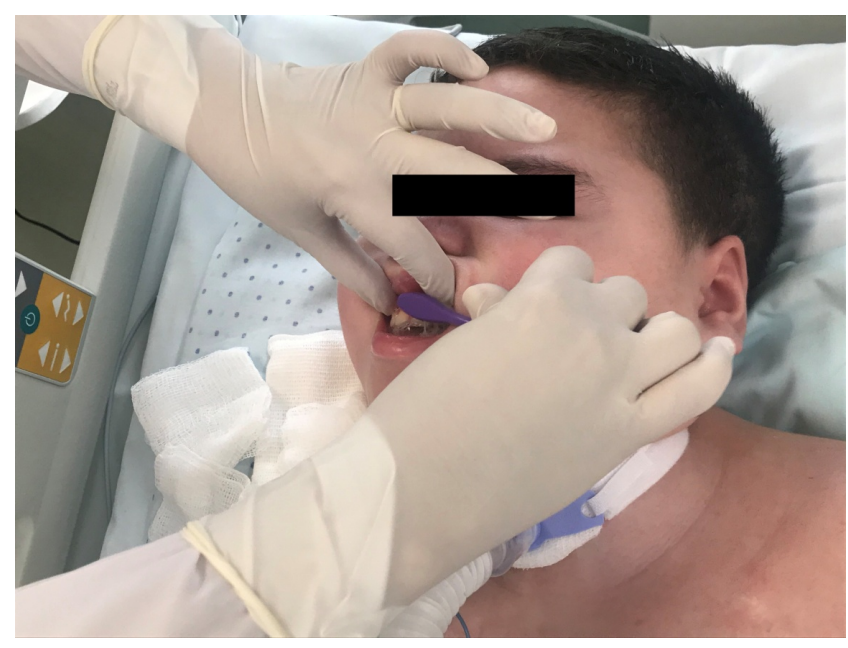

Figura 5. Profissional da odontologia hospitalar realizando profilaxia profissional durante visita semanal, para remoção da placa bacteriana e manutenção da saúde bucal.

A genitora, 28 anos, em sua terceira gestação, planejada, com acompanhamento médico, cartão de vacina atualizado, apresentou quadro de hipertensão gestacional e redução da movimentação fetal. O parto foi realizado por cesariana, sem intercorrências, com o bebê exibindo peso normal e choro ao nascer.

Ao ser questionada sobre a criança ter apresentado alguma sintomatologia horas após o nascimento, a mãe respondeu negativamente, mencionando que os primeiros sinais ocorreram após 26 dias do nascimento, citando palidez, cianose, dificuldade alimentar por sucção fraca e "choro igual a um gatinho novo".

Com relação aos aspectos odontológicos, a mãe declarou que o início da erupção dentária se deu aos seis meses de idade, e que as primeiras orientações de higiene bucal foram passadas em ambiente hospitalar, introduzindo a escovação nos cuidados prestados ao bebê. Quando indagada sobre a importância da odontologia para a melhora da qualidade de vida do filho, a genitora classificou como fundamental, e acrescentou "porque ele tava até com um dentinho para obturar e outros para tirar".

\section{RELATO DE CASO II}

Paciente J.L.S., sexo masculino, leucoderma, 8 anos de idade, natural do município de Olho d'Água- PB, internado atualmente na Unidade de Terapia Intensiva Pediátrica do Hospital Universitário Alcides Carneiro (HUAC) da cidade de Campina Grande-PB, apresentando dependência ventilatória total, com admissão datada em 20 de novembro de 2012, procedente do Hospital Regional de Emergência e Trauma Dom Luiz Gonzaga Fernandes, também em Campina Grande-PB, transferido entubado, acompanhado por médico anestesista, para esclarecimento diagnóstico de hipotonia muscular global, apresentando histórico de internamento por 15 dias no Hospital Infantil Noaldo Leite, na cidade de Patos-PB, após apresentar anóxia neonatal, e quadro clínico de desconforto respiratório importante.

Ao dar entrada no HUAC, recebeu parecer fisioterapêutico de atraso do desenvolvimento neuropsicomotor; hipotonia generalizada; e ausência de sustento cefálico. Tais condições apontaram a doença de Pompe e síndrome de Werdnig-Hoffman 
como hipóteses diagnósticas, sendo a primeira descartada por teste genético realizado por sequenciamento do gene GAA (alfa-glicosidase ácida), no laboratório CENTOGENE, com sede na Alemanha. Por conseguinte, foi considerado como diagnóstico principal a atrofia muscular espinal infantil tipo I (síndrome de WerdnifHoffman) associada à insuficiência respiratória crônica.

De acordo com a evolução médica atual, o paciente segue restrito ao leito, apresentando insuficiência renal crônica (ICR); epilepsia; puberdade precoce; hipovitaminose $D ;$ e hipertensão arterial sistêmica (HAS), com perda total da visão, como consequência do agravamento de tal circunstância. Em prontuário, citam-se também as infecções de âmbito hospitalar por Klebsiella pneumoniae e Pseudomonas aeruginosa como complicações durante o curso de internação.

Ademais, o menor mantém-se traqueostomizado, em dieta artesanal por sonda de gastrostomia, permanecendo em estado vegetativo, sem interação ou reação, dependente integral da equipe de enfermagem para cuidados rotineiros, que abrangem precauções com a VPM, horários regulares de dieta, higienização da cavidade oral com clorexidina aquosa, e administração de medicamentos para tratamento de crises convulsivas (fenobarbital 100mg) e para controle da hipertensão e prevenção de complicações cardiovasculares (anlodipino 5mg) (Figura 6).

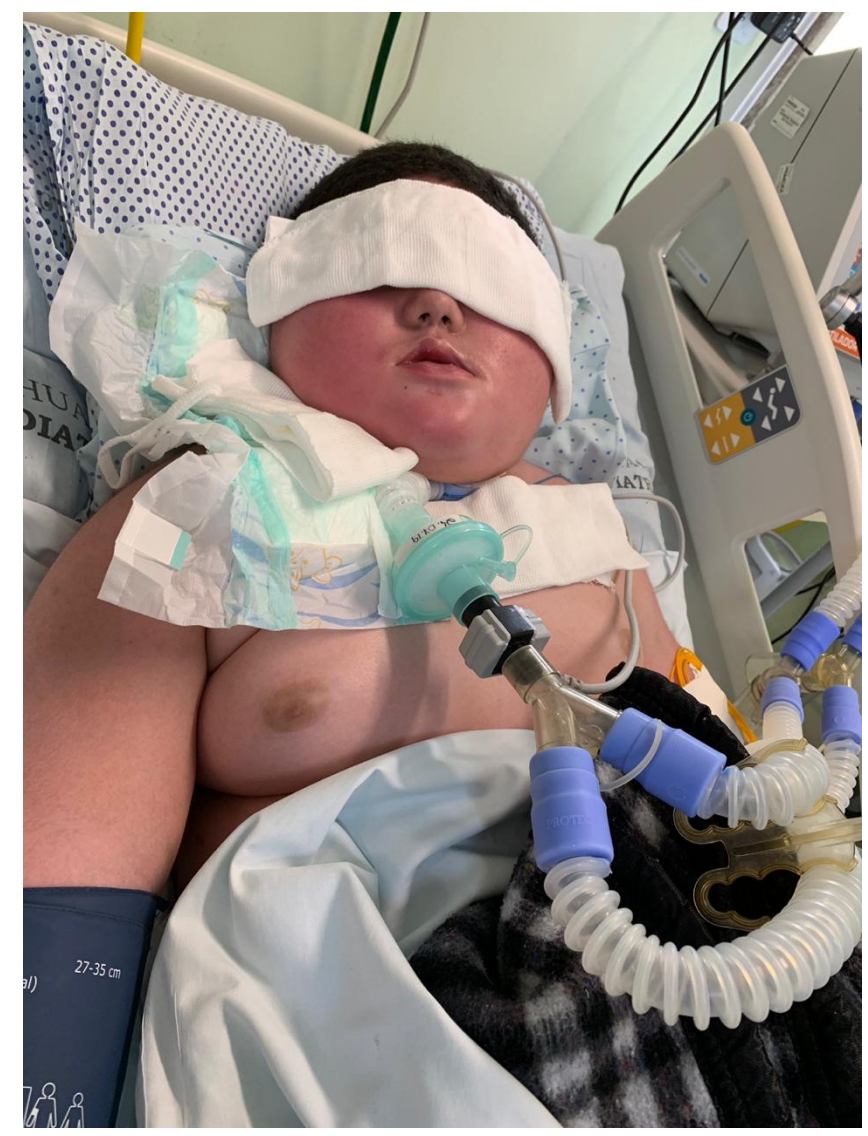

Figura 6. Paciente, traqueostomizado, com braçadeira de esfigmomanômetro para aferição de pressão arterial (procedimento de rotina da UTI).

Além dos cuidados ofertados pela equipe de enfermagem, outros profissionais acompanham o paciente diariamente, especificamente fisioterapeutas, com condutas de alongamento de membros, cinesioterapia passiva global e constante monitoramento das fasciculações da língua e disfagia, pois predispõem à aspiração pulmonar. O suporte psicológico também é disponibilizado, mas o paciente não esboça 
nenhuma reação diante dos estímulos que Ihe são direcionados.

No âmbito da odontologia hospitalar, além da prescrição de solução antimicrobiana, na qualidade de coadjuvante para manutenção da higiene oral, outras medidas preventivas são ofertadas, a exemplo da realização, com certa periodicidade, de uma profilaxia profissional na cavidade oral (Figura 7). Procedimentos mais invasivos também são recorrentes, visto que a idade do paciente é compatível com a fase de esfoliação dentária, necessitando de exodontias para anular o risco de aspiração. Em prontuário, constam as remoções cirúrgicas dos dentes $53,54,63,75$ e 85 , sendo todas elas autorizadas previamente pelo profissional da terapia intensivista, que analisa a condição sistêmica do paciente e sua capacidade de reagir satisfatoriamente ao plano de tratamento estabelecido pelo cirurgião-dentista, garantindo assim uma maior integração da odontologia e da medicina, visando o tratamento global do paciente (Figura $8 \mathrm{~A}$ e B).

Agregando às informações inicialmente passadas, a genitora respondeu a alguns questionamentos acerca da primeira infância do menor, relatando que ele é o sexto filho, fruto de uma gravidez planejada aos 33 anos, na qual recebeu acompanhamento médico, negando qualquer complicação durante período gestacional. A criança nasceu com peso corporal normal, de parto a ferro/parto fórceps, não chorando ao nascer, e apresentando limitação motora e anóxia.

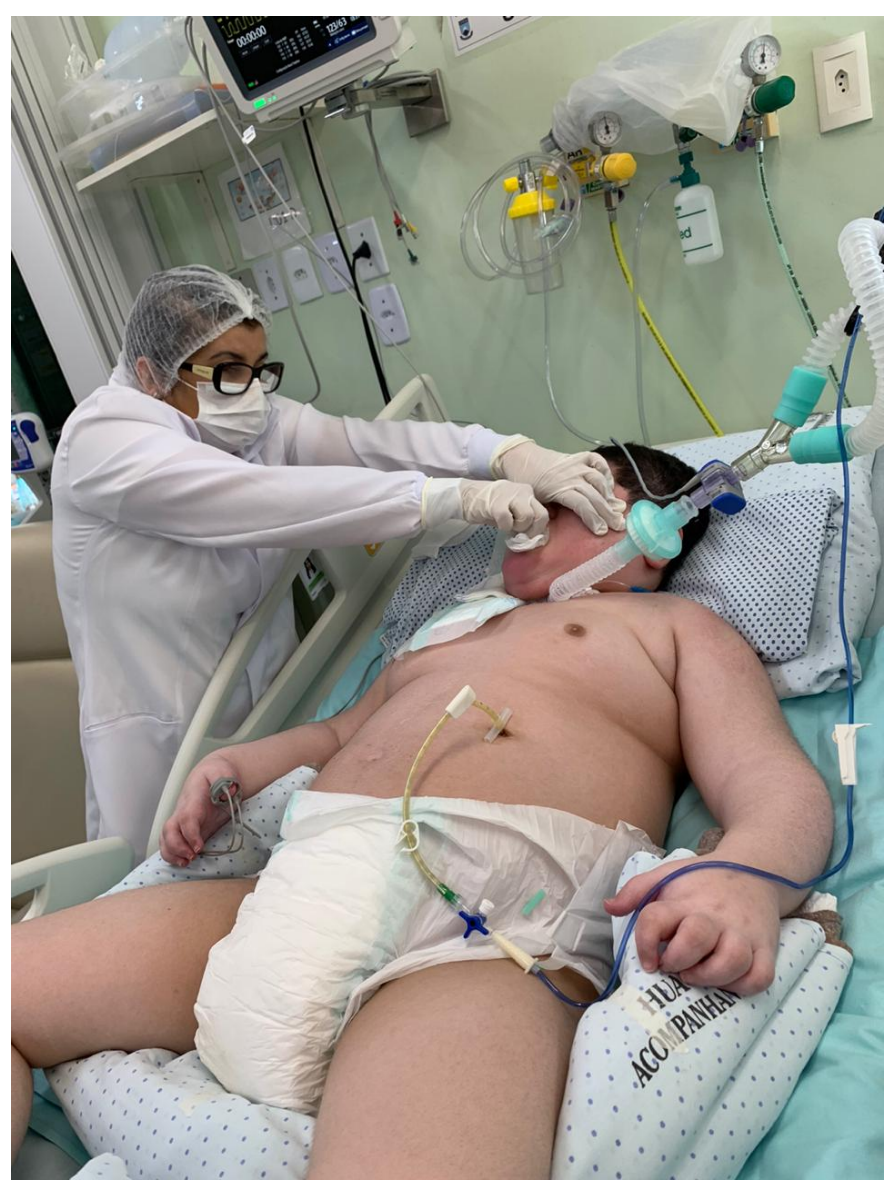

Figura 7. Higienização da mucosa oral mediante fricção de gaze umedecida com água destilada.

No tocante a saúde dentária do filho, a mãe informou que a erupção dental decídua teve início aos cinco meses de idade, iniciando a escovação nessa mesma época, aprimorando tal hábito após ter recebido, em ambiente hospitalar, correta orientação sobre higiene oral. Ainda sobre a temática, a genitora classificou a odontologia como importante para a melhora da qualidade de vida do filho, justificando com a afirmação "porque ele precisa fazer limpeza". 


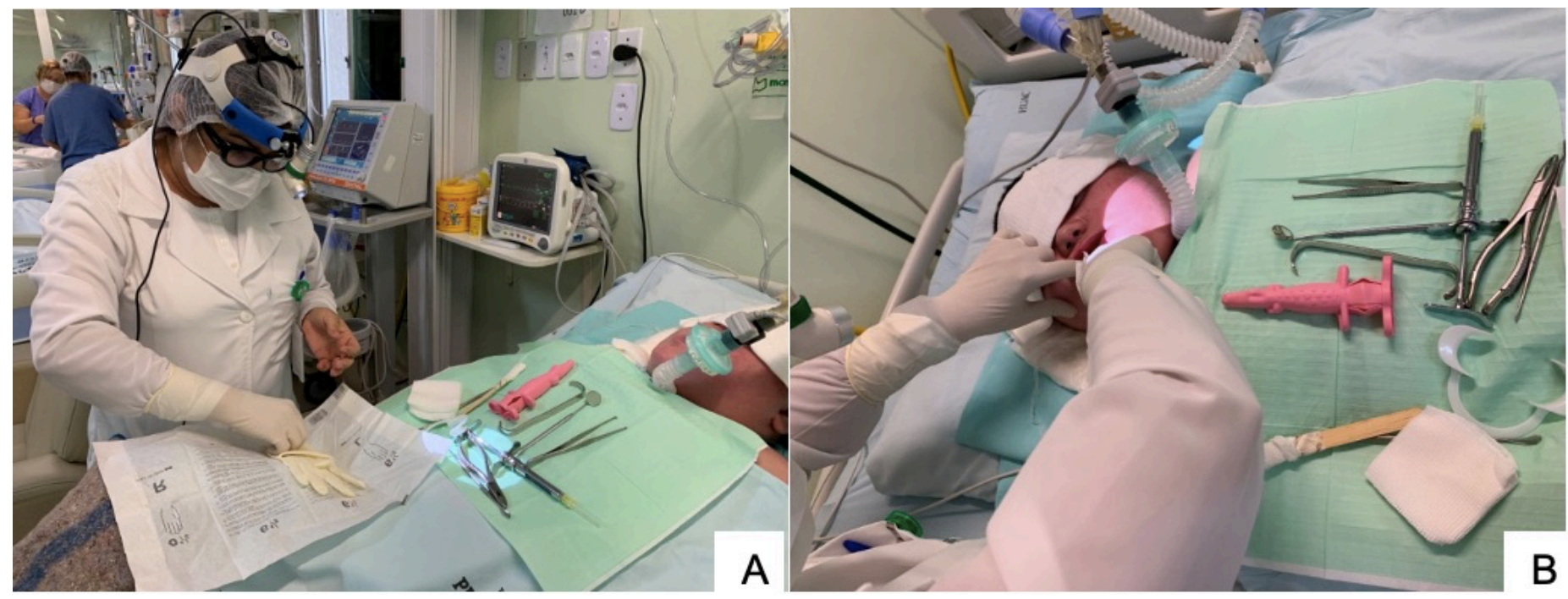

Figura 8. (A) Cirurgiã-Dentista se paramentando com luva cirúrgica estéril após escolha de instrumentais para o procedimento; (B) Realização de exodontia do dente 85.

\section{DISCUSSÃO}

As doenças neuromusculares são costumeiramente categorizadas em neuropatias ou miopatias. As primeiras são aquelas nas quais as células do nervo motor ou da ponta anterior da medula são afetadas de forma primária, resultando secundariamente em atrofia muscular, enquanto nas miopatias, a patologia envolve diretamente a musculatura, sem comprometimento de sua suplência nervosa. $^{4}$

A síndrome de Werdnig-Hoffman faz parte das doenças conhecidas como Atrofias Musculares Espinhais (AMEs), e, após a distrofia muscular de Duchenne, é a segunda forma mais frequente de doença neuromuscular da infância, ${ }^{5}$ sendo ocasionada por uma mutação genética nos cromossomos $5 q 13$, que promove desde características clínicas atenuadas, tais como choro fraco e tosse pouco efetiva, até uma série de limitações graves, como hipotonia extrema, que evolui com grave comprometimento respiratório e motor, ${ }^{3}$ com o óbito ocorrendo frequentemente no primeiro ano de vida, e com prognóstico desfavorável para aqueles pacientes que atingem faixas etárias maiores.

De importância para $\quad$ quadro odontológico, ressalta-se como achados clínicos: problemas na sucção e disfagia, em consequência da falta de força nos músculos da boca e do pescoço, e presença de fasciculações da língua. Devido à baixa expectativa de vida, o grande desafio é a sobrevivência dos pacientes, sendo necessário um suporte ventilatório e 
cuidados intensivos. Aliado a isso, através de uma equipe multidisciplinar, deve haver um conjunto de intervenções designadas para minimizar as complicações respiratórias da doença. ${ }^{6}$

Para tal, preconiza-se a prevenção de infecções respiratórias como conduta, sendo a prática odontológica fator de extrema importância para obtenção de resultados satisfatórios e uma possível melhora na sobrevida dos pacientes, tendo em vista que a boca é, naturalmente, um reservatório de bactérias por suas características de temperatura, umidade, $\mathrm{pH}$ e nutrientes, e que a principal causa de óbito nessa síndrome é a pneumonia hipostática ou aspirativa, ${ }^{7}$ que ocorre quando há aspiração de conteúdo gástrico ou secreções orais para o pulmão.

Atualmente, o diagnóstico preciso de pneumonia associada à ventilação mecânica (PAV) constitui-se de grande dificuldade e permanece como desafio constante para a prática clínica. $\mathrm{O}$ aspirado traqueal (AT), cuja colheita é uma das atribuições do profissional da enfermagem intensiva, é um método de obtenção de secreção traqueal para cultura e diagnóstico microbiológico da PAV. ${ }^{8}$
Fujitani $S^{9}$ (2011) e Niederman $M^{10}$ (2010) apontam em seus estudos que o AT ainda necessita de maiores comprovações científicas para o seu manejo, especialmente no que se refere às técnicas de colheita $e$ processamento microbiológico de suas amostras, pois ainda existem diversos protocolos e algumas questões ainda não resolvidas. A colonização fúngica e bacteriana da superfície interna do tubo endotraqueal (TET) em forma de biofilme é um dos fatores que mais desfavorecem para que as amostras não sejam representativas.

Zolfaghari PS ${ }^{11}$ (2011) afirmou em seu estudo que o biofilme pode ser considerado um agente pertinente em algumas infecções recorrentes, além de atuar como um reservatório de microrganismos que prejudica a análise microbiológica de conteúdos traqueobrônquicos e acarreta dúvidas na interpretação dos resultados de culturas quanto à contaminação, colonização e infecção. Permitindo e possibilitando vários acometimentos e doenças infecciosas, derivadas de outros fatores patológicos.

A saúde bucal de pacientes hospitalizados, sobretudo aqueles que permanecem por longos períodos, tem sido alvo de estudos, sendo esses preconizados pela Organização Mundial de saúde (OMS), uma vez que estabelecem a importância da saúde bucal para a saúde geral e melhora da qualidade de vida dessa população. ${ }^{12}$ 
Existe uma relação considerável entre o estado de saúde oral e aquele da saúde geral, comprovando-se em literatura uma relação entre a presença de doenças bucais com o surgimento e/ou a piora de condições sistêmicas. Dentre elas, podemos mencionar a associação entre doença periodontal e o agravamento de doenças cardiovasculares, diabetes, infecções bucais e pneumonia aspirativa, dentre outras. ${ }^{13} \mathrm{Em}$ pacientes hospitalizados essa relação assume importância ainda maior, pois o indivíduo encontra-se fragilizado pela doença que o levou à internação. ${ }^{14}$

O acompanhamento periódico do cirurgião-dentista para realização de procedimentos que removam focos de infecções é tão importante quanto à participação e a assistência dos familiares e dos outros membros da equipe multidisciplinar para manutenção da higiene bucal do paciente portador da síndrome de Werdnig-Hoffman, pois com o tempo de internação a quantidade de biofilme tende a aumentar, tornando-se uma situação preocupante por estar entrelaçada ao aumento de patógenos respiratórios que colonizam a placa bacteriana, contribuindo potencialmente para o desenvolvimento da pneumonia. ${ }^{15}$

\section{CONSIDERAÇÕES FINAIS}

Portanto, conclui-se que a saúde bucal é vital para a qualidade de vida e bem-estar geral dos indivíduos hospitalizados. É preciso prover a esses pacientes um tratamento multiprofissional e integrativo, sem separar a cavidade oral do restante do corpo, visto que as infecções bucais são importantes fontes de agravamento do quadro clínico de doenças sistêmicas. Nesse sentido, a presença de cirurgiões dentistas nas equipes multiprofissionais dos hospitais é de extrema importância para a implementação de protocolos clínicos de conduta visando tanto à prevenção quanto a recuperação da saúde bucal. 


\begin{abstract}
Purpose: To report the cases of two patients with the type I spinal muscular atrophy (SMA) or Werdinig- Hoffman syndrome, admitted to the Pediatric Intensive Care Unit of the Universitary Hospital Alcides Carneiro (UHAC) in the city of Campina Grande-PB. Case report: Male patients, both 8 years old, dependente on mechanical ventilation, presented early manifestation of atrophy and progressive muscle weakness, which prevented the development of motor skills, causing severe respiratory impairment. In the intensive care environment, in the context of a multidisciplinary team, the effect of the dental care service on promoting the quality of life of these patients stands out, acting especially in the control of pathogens. Conclusions: Oral disorders are potential sources of systemic worsening, must be prevented and resolved by a qualified dental surgeon working in a hospital environment, and willing to leverage the work of the multidisciplinary team, ensuring that care is integral.
\end{abstract}

\title{
KEYWORDS
}

Muscular Atrophy, Spinal. Neuromuscular Diseases. Dental Care.

\section{REFERÊNCIAS}

1. Perez ABA, Zanoteli E, Marrone CD, Rotta F, 12. Bilder L, Yavnai N, Zini A. Oral health status among Simões R. Amiotrofia espinhal: diagnóstico e aconselhamento genético. Brasília, Brasil: Projeto Diretrizes; 2011.

2. Han JJ, McDonald CM. Diagnosis and clinical management of spinal muscular atrophy. Phys Med Rehabil Clin N Am. 2008 Aug;19(3):661-80.

3. Marcondes E, Vaz FAC, Ramos JLA, Okay Y. Pediatria Básica Tomo II: pediatria clínica geral. 9 ed. São Paulo: Sarvier; 2003.

4. Fortes-Rêgo J. Doença de Werdnig-Hoffmann: 15 relato de dois casos. Arq. Neuro-Psiquiatr. 1976 Dec;34(4):387-393.

5. Fonseca LF, Pianetti G, Xavier CC. Compêndio de neurologia infantil. Rio de Janeiro: Medsi; 2002.

6. Patten J. Neuropatia periférica e doenças do neurônio motor inferior. In: Patten J. Diagnóstico diferencial em neurologia. 2 ed. Rio de Janeiro: Revinter; 2000. p.323-46.

7. Brandt S. Werdnig-Hoffmann's infantile progressive muscular atrophy: clinical aspects, pathology, heredity and relation to oppenheim's amyotonia congenita and other morbid conditions with laxity of joints or muscles in infants. Copenhagen, Munksgaard, 1950.

8. Shin YM, Oh YM, Kim MN, Shim TS, Lim CM, Lee $\mathrm{SD}$, et al. Usefulness of quantitative endotracheal aspirate cultures in intensive care unit patients with suspected pneumonia. J Korean Med Sci. 2011;26(7):865-9.

9. Fujitani $S, Y u$ VL. Quantitative cultures for diagnosing ventilator-associated pneumonia: a critique. Clin Infect Dis. 2006;43 Suppl 2:S106-13.

10. Niederman MS. The argument against using quantitative cultures in clinical trials and for the management of ventilatorassociated pneumonia. Clin Infect Dis. 2010;51 Suppl 1:S93-9.

11. Zolfaghari PS, Wyncoll DL. The tracheal tube: gateway to ventilator-associated pneumonia. Crit Care. 2011;15(5):310. long-term hospitalized adults: a cross sectional study. Peer J, 2014; 2:e423.

13. Kim J, Amar S. Periodontal disease and systemic conditions: a bidirectional relationship. Odontology. 2006;94(1):10-21.

14. Al-Emadi A, Bissada N, Farah C, Siegel B, AlZaharani M. Systemic diseases among patients with and without alveolar boneloss. Quintessence Int. 2006 Nov-Dec;37(10):761-5.

Willis PJ. The role of Dentistry in the hospital. J Am Dent Soc Anesthesiol. 1965;12(1): 40-4. 